\title{
Domestic Openness in Post-WTO China: Central and Local Perspectives*
}

\author{
Yingjie Guo
}

\section{Introduction}

In the lead-up to China's entry into the World Trade Organization (WTO) on 11 December 2001, commentators generally agreed that it would have a profound impact on the country's 'reform and openness' programme, although opinions diverged on the extent and nature of the impact. On the one hand, democracy advocates were adamant that Chinese accession would lead to deeper integration into the global economy and greater external openness, which would induce greater internal openness and translate into a driving force for political reform, ${ }^{1}$ speed up the progress of liberalization and democracy, ${ }^{2}$ or 'unleash forces that may hasten the demise of the mainland's one-party state' ${ }^{3}$ On the other hand, less sanguine analysts warned that greater external openness might trigger

\footnotetext{
* The author wishes to thank Louise Edwards, Elaine Jeffreys, Jeffrey.Browitt and Barbara Krug, who have read drafts of the article carefully and made invaluable comments. Thanks also to Margaret Tam for editorial assistance.

1 Viewpoint, 'Face up to Political Reform: Life under the WTO Will Require that China Change', Asia Week, Mar. 7, 2000.

2 This view has been articulated most eloquently by one of China’s leading liberal writers Liu Junning. See his article 'Classical Liberalism Catches on in China', The Journal of Democracy, 3 Nov., pp. 48-57.

3 Bill Clinton, speech to Democrats in New York on 21 May, 2000; cited in Heike Holbig, 'The Evolution of China’s Political System: New Rules for Communist Party Rule?’, Heike Hobig and Robert Ash (eds.), China's Accession to the World Trade Organization, London and New York: RoutledgeCurzon, 2002.
} 
major problems ranging from massive unemployment and social unrest to the total collapse of China's political and economic system. ${ }^{4}$

Needless to say, membership of the WTO has neither toppled the Chinese Party-state as yet, nor has it precipitated major social or economic disasters. But questions remain as to whether China is actually a more open society as a result of its WTO membership, in what way the WTO has affected reform and openness in China, and to what extent China's accession to the WTO is leading to political liberalization or translating into a demand for democracy. Curiously, nearly five years after China's accession, there is still little detailed research aimed at answering those questions. The scholarly reluctance to engage empirically with these issues seems primarily related to the magnitude of the change and the lack of transparency in China. Both features have made it difficult to assess the implementation of China's WTO commitments. ${ }^{5}$ Moreover, since the WTO

4 Analysts locate the causal factor of destabilization and social unrest in different areas of the WTO's potential impact. Minxin Pei, for example, suggests that social destabilization is likely to result from shortterm economic shocks of China's WTO entry, combined with obstruction by lower-level officials and bureaucrats. See Minxin Pei, 'Future Shock: the WTO and Political Change in China', Policy Brief, Carnegie Endowment, vol. 1, no. 3 (Feb. 2001). According to Shaoguang Wang, greater openness will entail the restructuring of the economy and inevitably lead to job losses and social conflict. See Shaoguang Wang, 'The Social and Political Implications of China's WTO Membership', Journal of Contemporary China, Vol. 9, Issue 25 (Nov. 2000), pp. 373-406. Gordon Chang's view is that the CCP will inevitably lose control of the economy under uncontrollable external pressure. Gordon Chang, 'Trade Charade: WTO Accession Will Trigger Collapse’, in The Coming Collapse of China, New York: Random House, 2001, pp. 187-88.

5 Kommerskollegium, National Board of Trade of Sweden, 'Executive Summary: China in the WTO--18 Months After the Accession', 12 Jun. 2003. Available at <http:www.kommers.se>. Accessed on 3 May 2006. 
implementation has been integrated into a broader national reform and openness programme, it is hard to separate the consequences of accession from those of other reforms. Still, it is evident that some of the changes to the Chinese political economy have been either generated or hastened by the WTO and in this regard it is now possible to see the contours, if not the full extent, of the WTO's impact.

This current article explores one key aspect of the WTO’s effect on reform and openness in Chin--the impact on domestic openness. Conceptually, 'domestic openness' covers a broad range of economic, social and political liberties and freedoms. For the purpose of this article, the concept primarily means openness to Chinese citizens as manifested by the removal or reduction of the Party-state's control of economic activity. It includes, in particular, decreasing state monopoly and bureaucratic intervention in market entry, exit and competition; improved legal regulation; and increasing transparency of trade-related rules and rule-making.

The article examines domestic openness at two levels, namely the central government's formal harmonization with WTO standards and the implementation of newly harmonized standards at the county level. This decision is based on two overlapping assumptions. First, while WTO-consistent laws and regulations provide a necessary framework for openness, it is crucial to understand their actual implementation not only at the national level but also at the grass-root level--particularly the county since it is the most basic level of governmental authority in China. Second, openness is likely to develop more quickly in big cities than in rural areas, and that the longer term significance of any openness that fails to penetrate to the vast countryside will be greatly compromised. 
In order to provide empirical data to inform this study, the article focuses on Dingzhou, a county-level city in central Hebei Province. Dingzhou has been selected primarily because since the 1930s social scientists have often considered it to be a fairly typical rural community in North China in terms of its demographic, social and economic conditions. ${ }^{6}$ In addition, as Dingzhou is close to both national and provincial centres, it is likely to feel the WTO's impact sooner than remote regions, and yet it may be less subject to dramatic change like that found in the Special Economic Zones or highly developed coastal regions. For these reasons, the changes here may be typical of changes in other counties in North China.

An analysis of national WTO-related reforms coupled with evidence from interviews with entrepreneurs, shop-owners and officials in Dingzhou indicates that WTO accession has already made considerable difference to reform and openness in direct and indirect ways. To date, the most consequential, direct result of WTO membership has been a new legal framework which encourages the uniform application of laws, transparency of rules and rule-making, non-discrimination, and openness. In addition, the direction and pace of reform are influenced as never before by external pressure, rather than predominantly driven by domestic logic, as China is obliged to implement its WTO obligations under international monitoring according to a fixed timetable. Perhaps even more far-reaching is the indirect impact of the WTO, which has, through a powerful 'WTO effect', generated additional pressure for reforms in areas not directly related to the WTO obligations.

\footnotetext{
6 For example, Dingzhou was one of counties selected in a comprehensive 'A social survey of 100 counties' by the Chinese Academy of Social Sciences (CASS) in 1987. In recent years, a research group from CASS has been monitoring economic development in Dingzhou as part of a CASS project on the economic ecologies of selected counties.
} 
It is evident, however, that the reforms have focused on the formal harmonization of standards while implementation has a long way to go and is impeded by numerous obstacles, particularly at the local level. Moreover, the openness resulting from the reforms is predominantly economic openness, which has not posed a serious threat to the dominance of the CCP or translated into a demand for political liberalization and democracy. These findings cast doubt on the common assumption that external openness somehow leads to internal openness or that political openness inevitably ensues from economic openness.

\section{A Better National Framework for Openness}

Much of the fundamental importance of China's WTO membership, as Vice Minister of Finance Jin Liqun has noted, lies in its capacity to change the way the Chinese Communist Party (CCP) manages the economy and governs the state. ${ }^{7}$ This is in part because the government, in order to gain WTO membership, had to make over 600 commitments, which entail a rule-based economy and a set of universal standards of trade and economic behaviour. ${ }^{8}$ Since the commitments are in many ways incompatible with longstanding

7 Jin Liqun, cited in 'China and the WTO One Year Later’, Harvard Business School, Working Knowledge, 21 Oct. 2002. <http://hbswk.hbs.edu>.

8 Clarke argues, in contrast, that 'there is no general obligation under the WTO agreements to have a fair and well functioning legal system'. See Donald C. Clarke, 'China’s Legal System and the WTO: Prospects for Compliance’, Washington University Global Studies Law Review, Vol. 2, No. 97, 2003, pp. 97-119: 112. See also Donald C. Clarke, 'Statement before the Congressional-Executive Commission on China', Washington, D.C., 6 Jun. 2002. Available at <http://www.cecc.gov/pages/hearings/060602/clarke>. Accessed on 11 May 2006. 
Chinese economic and political policy principles, the Party-state must make ideological and structural adjustments before it can fulfil its commitments. While many of Chinese commitments and reforms have benefited domestic openness, the most noticeable impact on it has stemmed from the rule-of-law commitments and administrative approval reforms.

\section{China's Rule-of Law Commitments}

Under the Protocol on the Accession of the People's Republic of China ('Protocol') and the Report of the Working Party on the Accession of China ('Report'), which set the terms for accession to the WTO, China is required

1. To conform central government laws, as well as all administrative and sub-national government regulations, rules, and measures to obligations undertaken in the WTO Agreement and the Protocol (Para. 2(A)3), Protocol);

2. To apply and administer in a uniform, impartial and reasonable manner all its national and local laws, regulations and other measures pertaining to or affecting trade in goods, services, trade-related aspects of intellectual property rights or the control of foreign exchange. (Para. 2(A)2);

3. To establish a mechanism under which both individuals and enterprises can bring to the attention of the national government cases of non-uniform application of the trade and foreign investment regime (Para. 2(A)4), Protocol);

4. To enforce only published laws and regulations and to make them available before they are implemented (Para. 2(C)1), Protocol);

5. To provide a reasonable period for comment after its laws, regulations and other measures by persons who may be affected (Para. 2(C)2), Protocol); 
6. To make transparent the administrative authorities in charge by publishing, in a designated official journal, a list of all organizations responsible for authorizing, approving or regulating service activities through grant of license or other approval, as well as the procedures and conditions for obtaining such licenses or approval (Para. 2(C)3), Protocol and Paras. 307 and 332, Report); and

7. To establish impartial and independent tribunals for the prompt review of administrative actions and review procedures including the opportunity for appeal, without penalty, by individuals or enterprises affected by any administrative action subject to review, and to provide contact points with respect to administrative actions (Paras. 2(D)1 and 2, Protocol).

These are clearly commitments to the core WTO principles of uniform application, transparency, reasonableness, non-discrimination, and judicial and administrative review of executive action. These principles not only demand openness to foreign businesspeople and enterprises but openness to Chinese nationals as well. The principle of uniform application, for instance, promotes domestic openness by insisting on legislative consistency and the uniform administration of all national and local legislation. A consequence of this is that departmental and local rules and policy measures inconsistent with higher-level legislation are no longer enforceable by law. Particularly pertinent to domestic openness is the removal of those elements that encourage local protectionism, restrict market entry and competition, or deny access to official information about economic policies and regulation.

The principle of transparency, as another example, requires that all trade-related laws, regulations, internal rules and other measures be made available to the public, and that the process of administrative decision-making be conducted on a basis that can be known. 
This helps reduce arbitrary uses and abuses or powers by officials as well as the confusion about legislation and administrative acts which ordinary Chinese citizens commonly experience. ${ }^{9}$ Coupled with this is the principle of reasonableness, which enables individuals and businesses to provide feedback on, and therefore influence, the laws, regulations and internal rules which may affect their operations. 10

Also significant is China's obligation to establish an impartial system for review of decision-making, which makes it possible for citizens to prevent improper measures from being incorporated into legislation in the first place and to seek judicial review of unacceptable administrative actions. To be sure, as analysts customarily observe, such a system may not emerge in the absence of an independent judiciary, and China is therefore simply not able to fulfil this obligation. That may be the case, but as far as openness is concerned, judicial independence is less important than due process and fairness. Theoretically at least, these are achievable in a system controlled by the Party-state especially in situations where its fundamental interests are not jeopardized as a result of impartial review. Moreover, there is no guarantee that a judicial system which is independent but corrupt will be more effective than one controlled by the CCP.

To a lesser extent, the principle of national treatment is also conducive to domestic openness, as China is obliged to 'progressively liberalize the availability and scope of the right to trade, so that, within three years after accession, all enterprises in China shall have

\footnotetext{
9 Jonathan Fried, cited by Sarah Biddulph, 'China’s Accession to the WTO’, in Sylvia Ostry et al. (eds.), China and the Long March to Global Trade - The Accession of China to the World Trade Organization, London and New York: Routledge, 2002, p. 154.

10 See paragraph 2C, Protocol.
} 
the right to trade in all goods...except for those listed in Annex 2A which continue to be subject to state trading' in accordance with the Protocol. (Para. 2(D)5.1, Protocol) One consequence of this is that the Chinese government is under pressure to put private entrepreneurs on an equal footing with the privileged state-owned enterprises (SOEs). ${ }^{11}$ Thus, a large number of economic sectors previously monopolized by SOEs must be opened to the private sector, and also private enterprises are entitled to the same preferential treatment accorded to the SOEs in terms of financing and pricing practices, taxation, market entry, resource distribution, and so on.

\section{Formal Harmonization with WTO Standards}

These commitments seem too ambitious to be met in the near future, given China's weak rule of law and institutional constraints. They certainly cannot be fulfilled unless the whole Chinese regulatory regime is made to conform to WTO norms and enforced at all levels of government. In what has been called the 'first step of China's WTO implementation', all existing national and local laws, regulations and normative documents which make up the Chinese economic regulatory regime have been reviewed, while those deemed inconsistent with WTO principles are either revised or repealed; and new ones are enacted where necessary. ${ }^{12}$

\footnotetext{
111 Part II, Report. China's chief WTO negotiator Long Yongtu apparently has a similar understanding of the non-discrimination principles. See Long, quoted by Ma Ke, in 'Minying qiye shifou dedao le "guomin daiyu”?' [Have non-state enterprises gained 'national treatment'?], Nafang zhoumo, 11 Nov. 2004.

$12 \mathrm{Ma} \mathrm{Yu}$ et al. (eds.), Zhongguo WTO Baogao [China WTO Annual Report], Beijing: Jingji ribao chubanshe, 2003, p. 11.
} 
While some reforms of the regime began long before China's entry into the WTO, external impact became increasingly visible starting from the mid 1980s, when China applied to rejoin the General Agreement on Tariffs and Trade (GATT) and then its successor, the WTO. Since 1998 the reforms have been deliberately aligned with WTO norms in anticipation of accession. ${ }^{13}$ By the end of 2000, the Ministry of Trade and Economic Cooperation (MOFTEC) had combed through over 1,400 laws, regulations, and normative documents. Of these, five statutes were to be revised, while 573 regulations were to be repealed and another 120 to be amended. ${ }^{14}$ In 2001 and 2002, thirty or so state ministries and commissions had reviewed some 2,300 national laws and regulations (of which 830 were repealed and 325 revised); ${ }^{15}$ the provincial-level governments and 49 big cities had sorted out more than two million local regulations and rules (of which over 200,000 were repealed); 16 and presumably many more had been dealt with by sub-provincial governments. The review was reported to 'have basically completed' by the end of June 2002. ${ }^{17}$

13 Ibid, p. 24.

14 Nan Xianghong, 'WTO: fa de chongxin goujia' (WTO: The Restructuring of Law), Nanfang Zhoumo, 25 Oct. 2001. Cited by Donald C. Clarke, ‘China’s Legal System and the WTO: Prospects for Compliance’, p. 104.

15 Zhang Xiangchen, 'Zhongguo rushi liangnianban huigu yu sigao' [Two and A Half Years After China Joined the WTO: Retrospection and Reflections], Zhanlue yu guanli 3, 2004. Zhang is an official of the WTO Department, Ministry of Commerce. Available at <http://www.cacs.gov.cn>. Accessed on 3 May 2006.

16 Ma Yu, China WTO Annual Report, pp. 24-25.

17 Ibid, p. 11. 
The effects of this comprehensive legislative review and revision on domestic openness can only be surmised until researchers have carefully compared a significant number of the new and old laws, regulations and other measures. It is reasonable to believe, though, that at least most of the elements that obviously contravene WTO norms and impede openness have been eliminated. As one turns to the new legislation enacted in the last few years, there is even more reason for optimism about China's formal harmonization with the fundamental WTO principles, including those directly related to domestic openness.

The aforementioned review has already done much to ensure legal conformity to the principle of uniform application. In addition, China's current Legislation Law lays unprecedented emphasis on the consistency of the legal system and clearly defines the legislative and rule-making powers of the People's Congresses at all levels, the State Council, central government departments, and local governments (Articles 7, 56, 63, 71 and 75). ${ }^{18}$ It also gives these state organs specified powers to repeal legislation enacted by state organs under their supervision if the latter have overstepped their powers, or if their legislation is inconsistent with higher legislation (Articles 87 and 88). Furthermore, to ensure consistency, the Legislation Law stipulates that laws prevail over administrative regulations, local regulations and normative rules (Article 79), while local regulations are higher than the normative rules of the government at the same level or below (Article 80).

18 Zhonghua Renmin Gongheguo Lifa Fa [The Legislation Law of the People’s Republic of China]. The statute was passed at the third session of the Ninth People's Congress on 15 Mar. 2000 and went into effect on 1 Jul. 2000. 
These requirements are spelt out in detail in two State Council documents released in 2001.19

By comparison, China's efforts to make its regulatory regime transparent are less impressive. The most important achievement so far is the Legislation Law. This statute not only requires the publication of all Chinese legislation but also wide consultation with 'relevant departments, organizations and citizens' during the law-making process (Article 58), in contrast to previous legislation, which did not impose similar requirements. Since 2000, every new law has included a clause on publication. Not only that, the requirement is now extended well beyond economic regulation as required by the WTO to all government policies, administrative rules and normative documents unrelated to the WTO obligations. 20

At the same time, the principle of non-discrimination has also been embedded in Chinese law, most notably in the Administrative Approval Law, the Government Procurement Law (2002), and the Trade Law (2004). But it is in the State Council circular released in 2005 where the principle of non-discrimination is endorsed most unequivocally and spelt out most clearly. In addition to allowing non-state-owned enterprises to enter any sectors open

19 The State Council, Xingzheng fagui zhiding chengfu tiaoli [Regulations Regarding the Procedure for Promulgating Administrative Regulations, 16 Nov. 2001 (to go into effect on 1 Feb 2002), and Guizhang de zhiding chengfu [Regulations Regarding the Procedure for Promulgating Normative rules and Measures], 16 Nov. 2001 (to go into effect on 1 Feb. 2002). Available at <http://www.china.org.cn/chinese/zhuanti/283938.htm>. Accessed on 25 May 2006.

20 See the State Council, 'Quanmian tuijin yifa xingzheng shishi gangyao' [The Implementation Outline for Comprehensively Promoting the Measures for Public Administrative According to Law], 22 Mar. 2004. Available at <http://search.people.com>. Accessed on 25 May 2006. 
to foreign operators, it states that private enterprises should be accorded equal treatment in investment licensing and approval, financing, taxation, land use, foreign trade, and so on. ${ }^{21}$ As a result of these changes, large parts of what was once the sole purview of the state have been opened up to private entrepreneurs, and their presence in an increasingly large range of economic activity has challenged state monopoly and rendered the CCP's 'socialist market' economic order more capitalist.

\section{Administrative Approval Reform}

China's endeavour to establish a WTO-consistent legal system is accompanied by a national administrative approval reform, which covers a broad range of administrative actions. The importance of this reform lies in the fact that administrative approval is 'the act that an administrative approval organ, upon application by a natural person, legal person or any other organization, permits the latter to undertake a specific activity, to recognize the latter's qualification, to confirm the latter's specific civil relationship or capacity to exercise a specific civil right and to undertake a specific civil act'.22 As such, it has been one of the Party-state's key mechanisms for maintaining economic, social and political control. In other words, what Chinese citizens can and cannot do largely depends

21 The State Council, 'Guanyu guli, zhichi he yindao geti saying deng feigong jingji fazhan de yijian' [Several Questions with Regard to Encouraging, Supporting and Guiding the Development of Private and Other Non-State-Owned Enterprises], State Council Circular, No. 3, issued on 19 Feb. 2005.

22 The Leading Group of the State Council on the Administrative Approval Reform, 'Guanyu luoshi xingzheng shenpi zhidu wuxiang yuanze de ruogan wenti' [Several Questions Concerning the Implementation of the Five Principles for the Reform of the Administrative Approval System], issued on 11 Dec. 2001. Available at <http://www.gd.gov.cn>. Accessed on 12 Oct. 2004. 
on the approval system and the discretion of the officials with the power to approve or not to approve.

The reform accelerated in October 2001, shortly before China entered the WTO, when the State Council issued the 'Opinions on the Implementation of Reform Work Concerning the Administrative System’ ('Opinions’). That initiative was followed up soon by 'Several Questions Concerning the Implementation of the Five Principles for the Reform of the Administrative Approval System’ ('Several Questions’). By January 2002, more than 4,000 matters subject to administrative approval at the national level had been reviewed, involving 65 ministries and departments under the State Council. ${ }^{23}$ Between November 2001 and May 2004, the number of such matters was reduced from 3695 to 1900 after 1627 were removed and 121 and 47 were respectively handed over to intermediate organs or professional organizations and local authorities. ${ }^{24}$ Importantly, compliance with the WTO commitments was one of the four essential criteria upon which the State Council decided whether to retain or abolish a particular approval. ${ }^{25}$

23 He Yong's interview in Fazhi Bao [The Legal Daily], 20 Mar. 2002, p. 1. He Yong was the deputy head of the Leading Group of the State Council on Administrative Approval Reform.

24 Huang Haixian and Han Bingjie, 'Zhengfu de "ziwo geming”'-- fang Guowuyuan xingzheng shenpi gaige lingdai xiaozu bangongshi zhuren'[The Government's 'Self Revolution--An Interview with Li Yubin, Director of the Office of Approval Reform Leading Small Group, the State Council], Liaowang xinwen zhoukan, no. 24, 14 Jun. 2004.

25 The other three criteria include: whether an approval was suited to the socialist market economy, whether it facilitated changes in the function of the government, and whether it helped reduce corruption. 
The reform culminated in the promulgation of the Administrative Approval Law (AAL) on 27 August 2003 (to go into effect on 1 July 2004). This landmark law stipulates that no administrative approval should be established for the following matters:

- those issues which can be decided by natural persons, legal persons or other organizations which will not infringe upon the state, social or collective interests or the lawful freedom and rights of other natural persons (Article 13.1);

- those issues which can be resolved through market competition (Article 13.2);

- those issues which can be resolved through normal and fair intermediate organs or professional organizations (Article 13.3);

- those issues which can be resolved through setting standards and strengthening subsequent supervision (Article 13.4).

Of even greater importance to openness, the AAL specifies that the People’s Congress and government bodies have the power to pass laws and rules which require citizens to obtain licenses or approval, determine the criteria upon which license or approval is to be granted or refused, dictate mandatory procedures for considering applications, and decide mandatory time limits within which applications must be processed. Furthermore, under this law affected citizens are entitled to an explanation as to the reasons their applications are not approved or their licenses or approvals are revoked, as well as the right to respond to and, in serious cases, institute an opportunity for a hearing.

\section{Improvements and Remaining Problems}

As a result of these reforms, the scope of administrative laws has been expanded considerably while the scrutiny of the legality of administrative decision has been 
strengthened. There is also a clearer definition of, and better check on, the powers of the central and local governments in legislation and administration, and less need for administrative approval. At the same time, entrepreneurs and enterprises are now in a position to influence the outcome of legal or administrative reconsideration. All in all, government control of economic and social activity is obviously reduced, while better safeguards against abuses of power and infringements on citizens' rights by Party and government organs and officials have also been devised.

Meanwhile, there remain numerous obstacles, including systemic problems, legislative lacunae, laws and regulations that are too general and vague to be easily enforced, and numerous other practical difficulties in implementation. Above all, judiciary review of administrative action is not likely to occur until China's political system has developed a clear separation of powers. ${ }^{26}$ This will continue to make it difficult for Chinese courts to accept cases where the defendant is the local government or an influential local official. Another main obstacle is persistent systemic opacity despite the recent improvements and the considerable discretionary power that Chinese officials have at their disposal. The problem is compounded by the lack of clarity and internal consistency in the legislation, and by the confusing relationships among numerous state organs with ill-defined and overlapping responsibilities. Therefore, it is not easy for ordinary citizens to feel confident about the legal parameters of their actions. ${ }^{27}$

\footnotetext{
26 Sylvia Ostry, China and the WTO: The Transparency Issue (online publication of the China/WTO Accession Project, University of Toronto, 1999.

27 Ibid.
} 
While the same problems exist at all levels of government, the WTO-related reforms at the local level seem to be following a somewhat different trajectory. The same observation can be made about the extent of broader notions of openness. This makes it all the more necessary to move beyond China's WTO commitments and administrative reform and find out whether the new laws and regulations are actually enforced and to what extent implementation is boosting openness.

\section{A More Open Dingzhou}

Dingzhou is situated between Baoding and the Hebei provincial capital Shijiazhuang, and is less than three hours' drive from Beijing and Tianjin. The county has 507 villages in its 22 townships and the suburbs of the county town, and with a population of just over a million, it is more populous than two average Chinese counties combined. Its rural population (nongye renkou) represents just over $80 \%$ of the total in contrast to the national ratio $58.2 \%$. Still, Dingzhou has sizable industrial and service sectors, whose contribution to the GDP in 2004 respectively amounted to $39.3 \%$ and $27.9 \%{ }^{28}$ In the same year, the county's GDP per capita reached 8,952RMB, exceeding the provincial average of 8,390RMB and approaching the national average of 9,057RMB. 29

As the WTO hype spread across China, the Dingzhou government took prompt action to implement the WTO commitments, although local officials seem to be more concerned

\footnotetext{
28 The Dingzhou Statistics Bureau, Dingzhou Tingjie Nianjian 2004 [Dingzhou Statistics Yearbook 2004], Dingzhou: The Dingzhou Statistics Bureau, 2005, p. 9.

29 These calculations are based on statistics in the Dingzhou Statistics Yearbook 2004 and at the County Economy website < http://www.china-county.org/zonglan/zonglan18.asp >. Accessed on 29 May 2006.
} 
with minimum compliance, which would exempt them from accusations of disobedience to higher authorities or non-compliance with WTO principles than with the spirit of the WTO obligations. Even before China acceded to the WTO, local government departments had organized numerous information sessions for their officials and public servants, and distributed a 'WTO study manual' to each government office detailing the WTO requirements, together with recommendations on how to adjust work practices accordingly. 30

On 13 November 2001, a ‘small leading group’ (SLG) was established to review existing policy measures and normative documents. ${ }^{31}$ The SLG's terms of reference specified that 'the scope of the review included all the normative documents of the local CCP organizations, the People's Congress, the government and government departments with respect to trade and services, that 'the aim of the review was to achieve compliance with higher laws and regulations and China's WTO commitments, particularly the principles of uniform application, non-discrimination and transparency’.32 Between November 2001 and May 2002, the SLG reviewed hundreds of documents and conducted a survey to find out how many approvals were being administered.

30 Interview with Mr Liu Wenkai, deputy Secretary General of the Dingzhou Party Committee, on 23 Nov. 2004.

31 The Small Leading Group for Reviewing Policy Measures and Normative Documents (SLG) comprised eleven members, including a deputy county Party secretary, a Vice Mayor, and nine heads or deputy heads of various departments. But the review was carried out by a group of young officials at the county’s Legal Affairs Section. Interview with Mr Xiao Baoyuan, former leader of SLG, on 26 Nov. 2004.

32 Ibid. 
The work took longer than expected not only because most of the departments did not have a clear idea what approvals each administered, but also because some departments deliberately omitted important approvals in their reports for fear of losing control. ${ }^{33}$ More approvals were reported only after the SLG reiterated that in the future it would not be possible to administer approvals excluded from a list to be published. ${ }^{34}$ Five months later, the SLG identified 41 documents and 161 administrative approvals no longer in effect or out of conformity with higher-level legislation or WTO principles. These were suspended or abolished between May and June.

On 13 October 2002, a delegation from the Baoding district government came to inspect Dingzhou's WTO implementation, and the delegation was satisfied with the progress. ${ }^{35}$ In April 2003, the government decided that the SLG had accomplished its mission and disbanded it. ${ }^{36}$ Since then the 'WTO hype' in Dingzhou has receded, but the implementation of WTO commitments actually grew more substantive between 2003 and 2004. Deeper implementation is still necessary not simply because the local government has a long way to go before achieving full compliance with WTO standards, but more importantly, it must try to keep up with the recent reform measures of the central, provincial and district governments.

\footnotetext{
33 Ibid, and interview with Mr Zhao Yongjian, former member of the group and chief of the Legal Affairs Section, 27 Nov. 2004.

34 Interviews with Mr Xiao Baoyuan and Mr Zhao Yongjian..

35 Zhao Yufeng and Xing Xiangdong, 'Baoding shi lingdao lai woshi shicha rushi gongzui' [Baoding Government Leaders Inspect Dingzhou's WTO Implementation], The Dingzhou Daily, 14 Oct. 2002, p. 1.

36 Interview with Mr Xiao Baoyuan, former leader of SLG, on 26 Nov. 2004.
} 
All the same, further reform here has continued to concentrate on areas where noncompliance is most easy to detect, such as the publication of regulatory rules, consistency with higher-level legislation, and administrative approvals. According to the official interviewed, following a series of reviews and revision, all of Dingzhou's local regulations and internal rules 'basically meet the requirements of upper-level governments and the WTO'.37 That claim is impossible to verify given the sheer number of documents involved and restricted access to the documents. There can be no doubt, however, that national and local laws, regulations and other measures are certainly not applied in accordance with their letter and spirit, as will be discussed later, whether or not local regulations and measures comply with central legislation and the WTO obligations.

Dingzhou's progress towards transparency is more obvious. In the last few years the publication of increasing numbers of policy measures and administrative rules, including four of five batches of abolished approvals, shows that greater transparency is encouraged. In a landmark decision in October 2005, the Dingzhou government allowed ordinary citizens to view and photocopy those normative 'red-headed documents' (hongtou wenjian) that contain no classified information. ${ }^{38}$ Needless to say publication is not tantamount to transparency - certainly if the publishing media are handicapped, as is the case with Dingzhou's main sources of official information, including the Dingzhou Daily, the government's website, a new electronic notice-board at Zhang Hanhui Square in the

37 Interviews with Mr He Feng, Secretary of the Dingzhou CCP Committee (23 Nov. 2204), Mr Xiao Baoyuan (26 Nov. 2004), and Mr Zhao Yongjian (27 Nov. 2004).

38 Zhao Yong, “'Hongtou wenjian” dui baixing kaifang' [Red-headed Documents Assessable to Ordinary Citizens], the Dingzhou Daily, 2 Oct. 2005, p. 1. 
county town, and notice-boards in government offices, in addition to government notices and newsletters.

Of these sources, the notice-boards in government offices are probably the most useful to the largest number of residents, as they can be found in government offices in the townships as well as the county town and provide easy access to a whole range of essential information about administrative actions, processes, fees and penalties. Next in the level of utility is the Dingzhou Daily, which is available at newsstands in the county town, although not in the townships or villages. The electronic notice-board publishes even more information with respect to public policy and administration, but few people come to the Square and it is not easy even for attentive passers-by to gather much information. The official website is no more effective partly because it is designed to attract investment and tourism from outside Dingzhou rather than to inform local residents about government actions that affect their lives, and partly because computers are still rare outside the county town.

The newsletters and internal, trade-related regulations, which are distributed exclusively to county government departments, the township governments, and district governments within the county town, are similarly difficult for ordinary citizens to access. While these various government bodies have the obligation to implement policies they have no obligation to disseminate the information, unless instructed to do otherwise. ${ }^{39}$ This means that many policy changes are not directly communicated to elected village committees or ordinary citizens. It is up to the citizens themselves to find the information themselves. The question remains as to how many people actually seek such detailed administrative

\footnotetext{
39 Interview with Gao Jie, Deputy Director of the Office of the Dingzhou Government on 25 Mar. 2006.
} 
information unless pressed to do so. Moreover, many others would be unaware that there have been policy changes of relevance to them, so they would be even less likely to go to the trouble of seeking out information on the reforms.

Given these problems, it is little wonder that there is a general lack of awareness amongst local residents about the government's WTO-related reforms. Of the 372 entrepreneurs, shop-owners and small business operators interviewed in the county town and the Lixingu, Xingyi and Qingfengdian townships between December 2003 and May 2006, 348 (93.5\%) did not know that the local government was bound by China's WTO obligations and national legislation to publish all its regulations and rules affecting trade in goods and services; 361 (97\%) were not aware that they could comment on new measures that might affect them; 337 (90.6\%) said they would probably not comment in the future if they were aware of new measures; 306 (82.3\%) had no idea if they needed licenses or permits after the approval reform; and 294 (79\%) was unsure how much they were supposed to pay in administrative charges, taxes and various other fess according to the rules.

Coupled with this prevalent lack of awareness is a common reluctance to seek clarification from officials who misuse their power, especially the grass-root officials carrying out routine checks on licenses, prices, hygiene, etc. at the local markets or isolated shops and factories. The story in the Dingzhou Daily of an unnamed owner of an audio-visual shop in a busy street in Dingzhou affords a good example of this problem. ${ }^{40}$ According to the report, the owner had been charged an average of 5,000 RMB in penalties every year in the previous few years, in addition to the 4,800RMB in 'national tax', the same amount in

40 'Yezhu dianzhu tu zhenqing' [Entrepreneurs and Shop Owners Tell the Truth], the Dingzhou Daily, 8 Aug. 2003, p. 2. 
'local tax', 3,600RMB in 'industrial and commercial administrative fees', and a 'hygiene fee' of 360RMB. These items added up to 18,560RMB, in contrast to her annual income of 5,987RMB. But it was never explained to her how these charges were calculated, and she never asked for clarification out of fear of offending the officials and incurring worse treatment.

Her situation, the report stresses, is not an isolated example, but a rather common occurrence in Dingzhou. Nor is the owner of the shop the only local resident who is reluctant to seek clarification from the officials, or appeal to the relevant government departs, or take legal action. In fact, the overwhelming majority of the entrepreneurs, shop-owners and small business operators interviewed in this study indicated that they would rather 'negotiate' (shangliang) with the officials than confront them, and in the end they would 'pay up' if the officials did not demand an excessive amount. And generally, the officials do not demand such an excessive amount that would provoke strong reactions, and they routinely ask for less if they are treated to dinner or told that no receipts are needed so that they can personally 'pocket' the money.

This finding is not in the least surprising; the average Chinese would rather rely on informal means to achieve desired objectives than seek redress through administrative or legal channels, either because of fear of retribution, lack of confidence in government departments or the courts, or because of traditional attitudes such as 'officials are high up and the people are low down'. ${ }^{41}$ This practice is obviously detrimental to transparency and openness in that it encourages unscrupulous officials to continue unreasonable and

\footnotetext{
${ }^{41}$ Huang Jie, 'On the Administrative Litigation Law', Chinese Law and Government, Vol. 24, No. 3, 1992, p. 43.
} 
unlawful acts. From the perspective of the grass-root officials, there is more to gain from opacity than transparency. Indeed, other than a moral sense or professional ethics, there is hardly any incentive to stick to the rules or make their work transparent, especially when considerable bonuses or their jobs are on the line if they fail to meet their assigned performance targets. 42

As compared with Dingzhou's implementation of the principles of uniform application and transparency, its administrative approval reform seems to have done much more to open the county up to the locals and businesspeople from outside. The scope of the reform is quite impressive: 1,121 approvals, or $84 \%$ of the total, have been abolished in five batches, in addition to 24 administrative fees. All these abolished approvals and fees have invariably led to greater openness, although their contribution varies. As a result, the local Party-state's control over economic and social life has been largely reduced, while business operators in Dingzhou, regardless of their origin, have gained the freedom to enter more and larger areas of the economy without Party-state intervention or interference sanctioned by law.

Of the 1,121 abolished approvals, 865 (77\%) are directly related to trade in goods and services, technical standards, and professional qualifications and salaries, and therefore to the WTO obligations. To non-local operators, an important benefit is that they can freely enter areas of the local economy, and like the locals, no approval is needed. In addition,

\footnotetext{
42 Officials in Dingzhou's township Industrial and Commercial Administration Offices have clear targets to meet. They usually work in pairs, and each pair is required to collect a hundred thousand RMB in 'administrative fees'. Any pairs who fail to meet their targets will lose an annual bonus ranging between 6,000 and 9,000RMB. If they fail for three years in a row, they can be sacked. Interviews with officials at the Xingyi and Lixingu ICAOs on 13 Apr. 2006, and at the Qingfengdian ICAO on 14 Apr. 2006.
} 
they stand to gain particularly from the removal of local protectionist approvals and fees. Any firms and companies are now free to set up offices in Dingzhou without approval. There is no need for representatives of any firms and companies to register with the local authorities. Amateur groups and professional troupes affiliated to state bodies above the county level from anywhere no longer need approvals to perform here. Non-local vehicles can pass through Dingzhou without being checked or paying fees. And departmental rules with regard to market entry by non-local operators are also removed.

\section{(Insert table here.)}

For local and non-local operators alike, of particular importance is the abolition of approvals which allows the export of thirteen types of foods and products, including technology, chestnuts and honey to all countries, chicken, port and beef to Hong Kong and Macau, and garlic to all countries and regions except South Korea (one of China's biggest garlic markets), although the export of other local foods and products is still monopolized by local and provincial state-owned companies. Still more important is the removal of approvals which enables entrepreneurs and enterprises to invest or engage in agricultural and forestry development; irrigation, transportation, energy and hi-tech projects; technology development; machinery and electronics manufacturing; and textile and other light industrial production.

At this stage, it is hard to judge the social significance of the new economic space that has been opened up in the reform, not least because it is not yet known how many entrepreneurs and enterprises are taking up that space. All available evidence suggests, though, that only a small number of businesspeople are starting to capitalize on the new 
opportunities. ${ }^{43}$ Further research and more statistics are required in order to get a better idea about the volume of economic activity in the open areas.

More apparent is the impact of the removal of approvals and fees on local business, as is evidenced by the steady decrease in the number of business licences revoked by the Dingzhou Industrial and Commercial Administration. In 2001, 311 licences were revoked in the county. The revocations dropped to 296 in 2002, 214 in 2003, 179 in 2004, and 163 in 2005. ${ }^{44}$ Even granting the possibility that more than one factor may be responsible for the decrease, one can safely assert that it has more to do than anything else with the dramatic reduction of businesses subject to annual inspection as part of the licence renewal process.

These optimistic perspectives are tempered by the existence of a serious problem with the local approval system. While the abolished approvals have been endorsed by the Baoding government, the retained ones have not. Nor are they published. But they are being administered regardless. 45 This evidently violates the Administrative Approval Law or the WTO principles. To make matters worse, though the government has set up an official

43 It is estimated that around 10\% of businesses since Jan. 2002 are engaged newly liberalized activities. Interview with Ms Su Linfen, deputy chief of Dingzhou Industrial and Commercial Administration on 24 Dec. 2005. Another estimate is 6-8\%. Interview with Mr Liu Shangwu and Ms Zhang Liyun, researchers at the Dingzhou Statistics Bureau, on 26 Dec. 2005. None of the township officials had any idea about this.

44 Interview with Ms Su Linfen, Deputy Director of Dingzhou Industrial and Commercial Administration on 24 Dec. 2005.

45 The retained approvals were submitted to the Baoding government for approval in Nov. 2004, but by 21 Apr. 2006, these had not been approved. Interviews with Mr Zhao Yongjian, former member of the group and chief of the Legal Affairs Section, on 21 Apr. 2006. 
enquiry point to handle queries about administrative approvals and fees, it seems to have deliberately left out the contact details--which can be found in the related internal documents--when the abolished approvals were published in the Dingzhou Daily. This author's requests to view the list of retained approvals at three government offices involved in preparing the list were declined on the grounds that it was an internal document. Exactly the same answer was given by officials at the other end of the enquiry hotline (2313871/2331585). In this case it is clear that non-compliance and lack of transparency are quite deliberate and systemic, even though practical difficulties around information dissemination are also partly to blame.

In short, Dingzhou has taken significant steps towards transparency, non-discrimination and openness during its WTO implementation, but in many areas it has achieved little more than minimum compliance with the WTO commitments while lagging further behind in others. Much remains to be done before the WTO`s potential impact becomes a reality.

\section{The Nature and Spread of Openness}

The discussion in the last two sections has demonstrated the WTO's most significant impact to date on reform and openness at central and local levels. Though the impact is hard to quantify, there is no denying that China has become a more open society today. On the other hand, WTO membership has not yet posed a serious threat to the Party-state or unleashed forces with the potential to send it crashing down in the near future. These developments have much to do with the nature and spread of various kinds of openness, 
such as external and internal openness, which can be further divided into economic, social and political subtypes. ${ }^{46}$

As has been argued, a host of different forces have driven domestic openness before and after the WTO accession. While China's own economic and political logic was primarily responsible for openness in the 1980s and 1990s, ${ }^{47}$ global integration has become a dominant driving force for domestic openness since Chinese accession to the WTO. To this extent, democracy and globalization advocates are well justified to anticipate greater openness in China as a result of its opening to the outside world. However, it is quite another question whether or not greater openness actually leads to political liberalization and democracy.

Typically, both democratization and globalization theories assume that political liberalization naturally ensues from economic liberalization and that liberalization somehow evolves into systemic change. Democratization theories often locate the key causal factor of democratization in changes in the economy, especially moments of rapid growth or economic crisis, and posit a causal relationship between free trade, economic growth, an expanding middle class, rule of law, openness, liberalization, and democracy. ${ }^{48}$

46 For a discussion of various types of openness and their relationships, see David SG Goodman, 'How Open Is Chinese Society?’, in David S.G. Goodman and Gerald Segal (eds.), China Rising--Nationalism and Interdependence, London and New York: Routledge, 1997.

47 David SG Goodman, ‘How Open Is Chinese Society?’.

48 See Seymour M. Lipset, 'Some Social Requisites of Democracy: Economic Development and Political Legitimacy’, American Political Science Review 53 (Mar. 1959). Adam Przeworski and Fermando Limongi, ‘Modernization: Theories and Facts', World Politics 49 (Jan. 1997).. 
In a similar vein, globalization theorists hold that increased trans-national flows of goods, money, ideas and people push national economic and political systems towards the 'ideal' combination of a market economy and a liberal democratic political system. ${ }^{49}$ Others speak of the end of the nation-state under the pressures and demands of a globalizing, capitalist economy. ${ }^{50}$ If one combines these with expositions of 'the end of history', it is hard not to conclude that the Chinese Party-state is doomed.

There is certainly no lack of like-minded pundits amongst Chinese liberals and democracy advocates and US policy-makers. As an example, Liu Junning, one of China's leading liberal writers, has argued forcefully that the WTO and private ownership, together with the internet, will give rise to democratization in China. 51 The China policy of the US over the last two decades, as another example, has rested on the belief that the power and rule of the CCP will be weakened by external openness and international interdependence, and that a democratic China will emerge in the wake of rapid economic growth and deeper integration into the global economy. ${ }^{52}$ This is well demonstrated in Bill Clinton's remarks, as quoted earlier, about the political significance of Chinese membership in the WTO.

49 See, for example, David Held et al., Global Transformations: Politics, Economics, and Culture, Stanford, Calif.: Stanford University Press, 1999.

50 Susan Strange, The Retreat of the State: The Diffusion of Power in the World Economy, Cambridge: Cambridge University Press, 1996.

51 Liu Junning, 'Classical Liberalism Catches on in China', The Journal of Democracy, 3 Nov., pp. 48-57.

52 Mary Gallagher, “'Reform and Openness”--Why China’s Economic Reforms Have Delayed Democracy’, World Politics 54, (Apr. 2002), p. 340. 
These suppositions may well be borne out in the long term. Whether they will be depends to a large degree on the nature and extent of openness and how it is spreading now, apart from prospects of revolutions or other dramatic events. As things in China stand, optimists are confronted with two major difficulties. First, the openness that has emerged in the implementation of WTO obligations is predominantly economic openness, which neither poses a significant threat to the Party-state nor easily translates into a demand for democracy. Second, the Dingzhou evidence shows that the WTO's impact on openness has been far less dramatic than most commentators predicted, that openness is not spreading far and wide enough to become a potent driving force for systemic change.

It is not surprising that the WTO has brought about more economic than social and political openness in China. After all, it is a trade organization whose essential function is to resolve conflicts of interests within and between member states and to facilitate free trade. Its rules 'do not mandate free speech or free press, and authoritarian Chinese policies limiting access to uncontrolled information remain legally unaffected' so long as discrimination between foreign and local providers does not occur. ${ }^{53}$ Additionally, the scope of the WTO regime is carefully restricted by acknowledgements that states can legitimately impose regulations, for reasons ranging from the protection of consumers to maintaining the overriding public interest or national security. It is even hard to see a strong mandate for institutional reforms from China’s WTO agreement. 54

53 M. Kantor, 'Foreign Direct Investment in Chinese Telecoms: Changes in the Regulatory Scheme', Cambridge Review of International Affairs 13 (2), 2000, pp. 136-151: 147.

54 See Donald C. Clarke, 'China’s Legal System and the WTO', and 'Statement before the CongressionalExecutive Commission on China’. 
This is not to say that Chinese entry into the WTO is politically insignificant. In fact, as has been pointed out, the 'WTO effect' has generated additional impetus for wider reforms, including political reforms, even in areas unrelated to WTO obligations. The 'WTO effect' has come about, first and foremost, because the Chinese government has deliberately used WTO membership as 'a shock therapy to destruct the old system and create a new one' and effectively swayed public opinion accordingly. ${ }^{55}$ At the same time, foreign governments and businesspeople as well as pro-reform Chinese officials at all levels of government and academics have urged the Chinese government to undertake reforms which are not required by the WTO as if they were. Additionally, numerous unrelated administrative matters have been reviewed alongside related ones and dealt with in the same package.

Social and political openness has also flowed from China's rule-of-law commitments and the resultant legal framework to ensure administrative transparency, reasonableness and fairness. This legal system, together with reduction of administrative control of economic activity, has meant stronger constraints on the government's ability to intervene in economic life and to control human freedom. Conversely, ordinary citizens are more independent of state organs or officials. Moreover, the government has not just produced a comparatively WTO-consistent trade regulatory regime but is also reshaping its legal system in other sectors in accordance with the same principles. Further change in this direction is most likely given that a good legal system is often an all-or-nothing proposition. 56

\footnotetext{
55 Similarly, Holbig argues that "WTO accession serves as an "external stick" for the leadership to assert itself against protectionist interests and to break deadlocks in the reform process.' See Heike Holbig, p. 171. 56 Donald C. Clarke, 'Statement Before the Congressional-Executive Commission on China’.
} 
In addition, some economic openness, such as the opening of state-monopolized sectors to private entrepreneurs, has clear political implications. As a consequence of growing involvement by the private sector, the Chinese 'socialist market economy' has become more capitalist, but that is precisely the sort of change that the CCP has been pursuing for over two decades albeit with the occasional temporary setback. There are also instances where economic openness is political openness at the same time. This is the case with numerous freedoms to engage in cultural or entertainment services without prior approval, such as the freedom for individuals and firms to establish live performance venues or film or television studios and to perform in public, and for professional and adult education colleges to decide their own curricula. While these freedoms may lead to an increase in cultural or education content unacceptable to the Party-state, at this stage that content is not likely to pose a serious threat to the CCP or translate into a demand for democracy not least because its impact will remain limited for some time.

In any case, it is hard to imagine that the CCP would allow these freedoms to escalate into a significant challenge to its rule without intervening. In fact, throughout the reform era, the CCP has continued to contain the political impact of openness while trying to reap the benefit of foreign trade, investment and technology. ${ }^{57}$ Likewise, it has moved quickly to

\footnotetext{
57 David SG Goodman, ‘How Open Is Chinese Society?’, p. 29. Holbig argues similarly that while the CCP has relaxed its control of information and connived at the pluralization of values, interests and lifestyles, it continues to curb political openness and any attempts of articulation and organisation of social interests with the potential to become politically effective. See Heike Hobig, p. 162. Gallagher believes that 'China's Communist leaders have made growth and globalization work for them.' See Mary Gallagher, 'Reform and Openness--Why China’s Economic Reforms Have Delayed Democracy’, pp. 338-72: 340.
} 
increase measures against subversion in anticipation of destabilizing effects of WTO membership. ${ }^{58}$ In September 2000, barely seven months after the conclusion of the ChinaUS agreement on accession, the Chinese government introduced a raft of regulations, which proscribed a long list of crimes, including activities that 'violate the fundamental principles of the constitution', 'jeopardize national unification', 'disrupt the unity between the different ethnic groups', 'sabotage state policy on religion by propagating feudal beliefs', or 'endanger social stability'.

Worse still, not only has the pressure emanating from China's WTO membership generated limited political openness, but much of it has leaked or has not transmitted through the complicated economic regulatory system. Most leakages and blockages occur when the newly harmonized national standards are implemented within the context of economic and political institutions of the local government, each with its own imperatives, priorities and vested interests. For example, the aim of the approval reform, from a central government perspective, is to open up the market and encourage competition, to combat corruption and to move towards 'small government, big society'. 59 Yet, the Dingzhou government has shown little interest in facilitating fair competition and instead protects the monopoly of Dingzhou's 'pillar enterprises' in order to secure its tax revenue and other interests. 60 Similarly for the approving authorities and the grass-root officials

\footnotetext{
58 Dali Yang, 'China in 2001: Economic Liberalization and Its Political Discontents’, Asian Survey, Vol. 42, ISS. 1 (Jan-Feb 2002).

59 The Leading Group of the State Council, ‘Several Questions'. See also See He Yong’s interview in Fazhi Bao [The Legal Daily], 20 Mar. 2002, p. 1.

60 The Dingzhou government makes no secret of this. For its preferential and protectionist measures, see 'Investment Guide’ in <http://www.dingzhou.gov.cn/touzi.htm>. Accessed on 6 Jun. 2006.
} 
carrying out routine checks, there is much to lose from the reduction of approvals and transparency but little to gain from implementing national standards and policies. It is also hard to imagine why they would want to support 'small government, big society' or anticorruption measures at their cost.

Similarly, the Dingzhou government has come under far less external pressure than the central government. One reason for the latter's prompt implementation of its WTO obligations is mounting international pressure, particularly from the WTO and US government agencies and businesses. Since 2002, the subsidiary bodies of the WTO and its General Council have reviewed Chinese implementation annually, and the review will take place every year for eight years. The US maintains a comprehensive monitoring programme through the Trade Policy Staff Committee's (TPSC) Subcommittee on China WTO Compliance, in addition to top-level dialogues. The TPSC comprises experts from the US Trade Representative's office, the Departments of Commerce, State, and Agriculture and Treasury, among others. It works closely with attaches at the US Embassy and Consulates General, who diligently gather WTO-related information, liaise with American industries in China, and regularly raise American concerns with Chinese officials at key ministries and agencies.

In contrast, the Dingzhou government has not been subjected to the same kind of scrutiny, and international monitoring agencies most probably will not take an interest in the WTO implementation in the counties for the simple reason that not much is at stake there. That is not to say that there are no foreign businesses in Dingzhou, but the volume of foreign business is very small--in fact, there were no more than 2 small-scale foreign operations 
and 5 small-scale joint ventures here in $2005 .{ }^{61}$ Besides, it is local government policy to accord more favourable treatment to foreign businesses than to Chinese ones and to ensure that foreign operators are granted licenses almost automatically and are effectively insulated from intervention or interference from government departments or officials. 62 Therefore, there is no need for them to demand the implementation of the WTO principles--the equal treatment provisions least of all.

The only monitoring effort in Dingzhou has been an inspection by a delegation from the Baoding district government. However, in a session that lasted less than two hours all that the delegation did was listen to oral reports by local officials on the review of current regulations, internal rules and policy measures including the first batch of abolished approvals. ${ }^{63}$ Without looking at the content of the large number of existing documents under review, it was impossible for the delegates to see if they comport with the WTO principles and national legislation, to say nothing of Dingzhou's overall implantation, which the oral reports did not cover. And yet, the delegation was ready to declare satisfaction with the WTO implementation there. This seems to suggest that the inspection was nothing but a perfunctory exercise that failed to press for more than minimum compliance. To make things worse, the Dingzhou government is under little pressure from local businesspeople and citizens to fully comply with the WTO obligations, as discussed

61 The Dingzhou Statistics Bureau, Dingzhou Tingjie Nianjian 2005 [Dingzhou Statistics Yearbook 2004], Dingzhou: The Dingzhou Statistics Bureau, 2006, p. 220.

62 For its preferential treatment to foreign operators, see 'Investment Guide' in <http://www.dingzhou.gov.cn/touzi.htm>. Accessed on 6 Jun. 2006.

63 Interviews with Mr He Feng on 23 Nov. 2004, Mr Xiao Baoyuan on 26 Nov. 2004, and Mr Zhao Yongjian on 27 Nov. 2004. 
earlier. It is little wonder, then, that Dingzhou's WTO implementation has lost momentum now even though it has some way to go before catching up with the national reforms.

\section{Conclusion}

In sum, Chinese accession to the WTO has already had a profound impact on domestic openness in China, although the impact is not as dramatic as many expected. Thus far greater openness has resulted most notably from a series of administrative reforms and a new trade regulatory regime, which have gone a long way towards uniform application, transparency, non-discrimination and impartial judiciary review, reduced ideological and administrative control over economic activities, and expanded the scope of rights and freedoms protected by law.

The WTO has generated this impact on the strength of a legally binding agreement, which has spelt out China's obligations to be fulfilled according to a fixed timetable. This is evidently an effective way of achieving global integration. Coupled with this is effective international pressure and monitoring. In addition, there is a large degree of congruence between the Chinese governments' reform agenda and most of the WTO fundamental principles. Without this, China probably would have been less keen to join the WTO and its WTO implementation would have met with far more difficulty than it has to date. The varied depth and scope of WTO implementation at principles at the central and local levels are attributable to differences in these factors. Simply put, the better the congruence between the WTO principles and the domestic logic and the stronger the pressure, the more successful the WTO implementation. 
In all likelihood, China's economic and political reforms will continue in the years to come with or without intervention by the WTO and the international community at large, and consequently openness will expand further. Nevertheless, sustained efforts to hold the Chinese government to its WTO commitments will make a big difference to economic, social and political change and openness in China by pressing it to move beyond formal harmonization and minimum compliance towards full implementation of both the letter and spirit of the WTO commitments as well as effective enforcement of WTO-consistent laws, regulations and other measures in accordance with their content and purpose. If all levels of government are left to their own devices, further progress is less likely to take place, especially in areas faced with stiff challenges, including transparency, nondiscrimination and independent judiciary review.

Major external and internal sources of pressure include the WTO, member states, foreign businesspeople, higher-level governments, and Chinese citizens. Of these, internal pressure is obviously most indispensable to sociopolitical change. For example, if the Baoding district government had taken its monitoring effort more seriously and demanded better implementation of the WTO obligations in Dingzhou, the county government would most probably have obliged. To a lesser extent, pressure from Dingzhou citizens can also force the local officials to do a better job. Although they remain powerless quite often visà-vis the government, WTO membership has presented new opportunities for selfempowerment and administrative improvement. Unfortunately, higher-level authorities like the Baoding government have little incentive to demand more than minimum compliance from the lower-level governments, while deep-rooted attitudes amongst local residents are standing in the way of sociopolitical change. It might take years to foster a form of active citizenship that helps make government more transparent, reasonable and accountable. 
For these reasons alone, there is a clear need for external pressure. External pressure is potentially more effective for three he reasons. First, it is lawful and legitimate and therefore cannot be dismissed out of hand as interference in China's internal affairs, as is often the case with international criticism of human rights abuses in the country. Second, international monitors are unlikely to ignore or connive at non-compliance, in contrast to less interested inspectors from higher-level governments. And finally, international pressure can be applied to all levels of government in accordance with the Protocol. Given that the main stake of international players is concentrated in big cities, it is easy to understand why they have not paid much attention to WTO compliance at the local level. It is harder to understand why foreign governments who are keen to encourage liberalization and political change in China, particularly the US, are slow to capitalize on the opportunities that the WTO has presented. Systematic implementation of WTO principles at all levels of governments is surely more effective for that purpose than occasional criticism of the Chinese government's human rights record. 
Table: Administrative approvals abolished in Dec. 2001, Oct. 2002, Mar. 2003, Nov. 2003 and Oct. 2004

\begin{tabular}{lcccccc}
\hline \multicolumn{1}{c}{ Categories } & \multicolumn{7}{c}{ Number (in 5 batches) } & \% \\
& 1 & 2 & 3 & 4 & 5 & \\
\hline Agriculture, forestry and livestock (60) & 7 & 12 & 2 & 29 & 10 & 5.4 \\
Archives (18) & 1 & 0 & 14 & 0 & 3 & 1.6 \\
Civil affairs (31) & 5 & 2 & 1 & 11 & 12 & 2.8 \\
Culture, sports and tourism (83) & 3 & 3 & 25 & 19 & 33 & 7.4 \\
Economic development and & & & & & & \\
planning, trade, and investment (227) & 16 & 26 & 49 & 89 & 27 & 20.2 \\
Education and training (22) & 7 & 1 & 3 & 4 & 7 & 2 \\
Environment (34) & 5 & 2 & 5 & 19 & 3 & 3 \\
Finance, taxation and pricing (82) & 14 & 18 & 14 & 12 & 24 & 7.3 \\
Industry and commerce (46) & 9 & 12 & 10 & 7 & 8 & 4.1 \\
Labour and personnel (62) & 24 & 17 & 12 & 4 & 5 & 5.5 \\
Land and water resources (33) & 0 & 5 & 11 & 5 & 12 & 2.9 \\
Public health (46) & 0 & 4 & 6 & 16 & 20 & 4.1 \\
Public security (79) & 15 & 0 & 37 & 16 & 11 & 7 \\
Radio and TV broadcasting (10) & 0 & 0 & 3 & 7 & 0 & 0.9 \\
SOEs and TVEs (26) & 13 & 9 & 0 & 2 & 2 & 2.3 \\
Technical standards (70) & 0 & 1 & 3 & 53 & 13 & 6.2 \\
Transport and telecommunications (61) & 15 & 27 & 5 & 8 & 6 & 5.4 \\
Urban development and planning (118) & 25 & 4 & 55 & 25 & 9 & 10.5 \\
Other (29) & 2 & 0 & 2 & 3 & 22 & 2.5 \\
\hline Total: 1121 & $\mathbf{1 6 1}$ & $\mathbf{1 4 3}$ & $\mathbf{2 5 7}$ & $\mathbf{3 2 9}$ & $\mathbf{2 3 1}$ & $\mathbf{1 0 0}$ \\
\hline
\end{tabular}

Source: Dingzhou ribao [The Dingzhou Daily], 20 Nov. 2001, 23 Oct. 2002, 9 Jul.2003, and Dingzhou shi renmin zhngfu gonggao [Dingzhou Government Announcement], 20 Nov. 2003, and 21 Oct. 2004. 